\title{
The Implementation of the Reading to Learn Strategies in the Teaching of Short Stories Reading Compehension Achievement at SMPN 3 Medan
}

\author{
Masitowarni Siregar ${ }^{1}$, Baharuddin $^{2}$, Endang Matulissa ${ }^{3}$, Nelly Marlina Tampubolon \\ Lili Sartika $^{4}$, Dimas Hendrawan $^{5}$ \\ 1,2,3,4,5Universitas Negeri Medan, Indonesia \\ Email: masitowarnisiregar@unimed.ac.id
}

\section{Abstract:}

The aim of this endeavour is to find out: (1) Planning for learning about short stories using the Reading to Learn Approach); (2) Implementation of learning Short Stories using the Reading to Learn Approach. This study uses a qualitative descriptive method that emphasizes the process and meaning of ongoing activities. Data were collected through observation, field notes, interviews, and document analysis. Data validity was carried out through method triangulation and source triangulation. The research findings indicated that the teacher had carried out good preparation in planning $R 2 L$-based learning, namely by preparing learning preparataions in lesson plans formats, teaching materials, worksheet, assessments and learning media, The teacher also informs the students beforehand that the teacher would implement a new learning model in which it is hoped that all students would fully participate in the class later. At the implementation stage of learning the teacher had followed the R2L learning steps by Rose and Martin (2012), namely Preparation, Detailed Reading, Joins Construction and Individual Construction.

Keywords:

reading to learn approach; literacy; short stories

\section{Introduction}

Based on the findings of the Program for International Student Assessment (PISA) survey the literacy skills of Indonesian students do not develop for 18 years. In 2000 the literacy competency score of Indonesian students at PISA was at 371. Then 18 years later, the number is still exactly the same in 2018 where Indonesia is ranked 74 th out of 79 countries. The results of the 2018 PISA Survey released in 2019 show that basically, Indonesian learners have very minimum competency in (1) comprehending complicated news, (2) theory, sythesis, and how to solve problems, (3) utilizing instruments, procedures, and problem solving, and (4) making research. Based on the facts above, it is necessary to change the system in the process and studying. The learning and assessment developed by the educator are assumed to be able to elevate higher-order thinking capabilities, improve creativity, and formlearners' competencies to have resolutions to problems.

One of the efforts to improve students' reading literacy in Indonesia is the Literacy Improvement Program for students in Indonesia at the junior high school level by the Ministry of Education, Culture, Research and technology which aims to Develop teacher competence in teaching and solving literacy assessments in reading, science and mathematics to improve students' literacy competence. 


\section{Linglit Journal: Scientific Journal of Linguistics and Literature \\ ISSN: 2774-4523 (Online), 2774-4515 (Print)}

Vol. 2, No. 4, December 2021, Page: 199-207

Email: linglitjournal@gmail.com

One of the goals of the program is to introduce the use of The R2L Strategies initiated by Rose, D \& Martin, J. (2012) to address the problem of reading literacy in Indonesia, where the $\mathrm{R} 2 \mathrm{~L}$ approach has been successful in many countries in increasing reading literacy. After going through the Workhsop process to introduce The R2L Approach to teachers, an implementation program was carried out to see how teachers were able to implement this approach and how to increase students' reading literacy competence as well as teacher and student perceptions of this approach.

For this reason, with a collaborative research scheme, collaboration between universities, namely Medan State University and State Junior High School 3, this research is carried out which seeks to uncover various issues including the ability of teachers to plan, carry out learning, followed by discovering how teachers and students perceive this approach as well as problems what arises in the implementation of the R2L Approach which is still newly introduced in Indonesia.

The implementation of the R2L Approach was carried out on learning competence reading short stories because reading short stories can be the basis for students' ability to read other stories. For example, reading novels, reading biographies, reading autobiographies, and so on. Another reason for choosing short stories is that so far students tend to be less interested in reading short stories. This can be seen during the teaching and learning process of literature. When students are given short story appreciation materials, it is very difficult for them to name the actors, setting, characters of the characters, and the theme of the story. Likewise, in learning literature, students are expected to be able to provide an explanation of the thoughts, ideas, imagination of the authors, so that students understand and understand the contents of short stories.

To achieve the expected curriculum goals in short story appreciation learning, teachers, especially teachers, are required to provide appropriate learning methods so that they can be used as minimal means to get maximum results. This is stated in (Sagala, 2004:63) that "As educators must understand various learning models that can stimulate students' ability to master the subject matter".

The results of the Program for International Student Assessment (PISA) survey show that the literacy skills of Indonesian learners do not develop for 18 years. In 2000 the literacy competency score of Indonesian students at PISA was at 371. Then 18 years later, the number is still exactly the same in 2018 where Indonesia is ranked 74th out of 79 countries. The results of the 2018 PISA Survey released in 2019 show that in general, Indonesian learners are very low in (1) comprehending complicated data, (2) formula, synthesis, and problem resolution, (3) utilzing instruments, procedures, and problem solving, and (4) making investigations. Based on the facts above, it is necessary to change the system in the process and learning. The learning and evaluation made by the educator are expected to be able to elevate higher-order thinking competencies, improve creativity, and develop learners' independence to clarify problems.

According to Astuti et al (2019) Education is an obligation of every human being that must be pursued to hold responsibilities and try to produce progress in knowledge and experience for the lives of every individual. Education is one of the efforts to improve the ability of human intelligence, thus he is able to improve the quality of his life (Saleh and Mujahiddin, 2020). Education is expected to be able to answer all the challenges of the times and be able to foster national generations, so that people become reliable and of high quality, with strong characteristics, clear identities and able to deal with current and future problems (Azhar, 2018). 
One of the efforts to improve students' reading literacy in Indonesia is the Literacy Improvement Program for students in Indonesia at the junior high school level by the Ministry of Education, Culture, Research and technology which aims to Develop teacher competence in teaching and solving literacy assessments in reading, science and mathematics to improve students' literacy competence.

One of the goals of the program is to introduce the use of The R2L Approach, which was initiated by Rose, D \& Martin, J. (2012) to address the problem of reading literacy in Indonesia, where the $\mathrm{R} 2 \mathrm{~L}$ approach has been successful in many countries in increasing reading literacy. After going through the Workhsop process to introduce The R2L Approach to teachers, an implementation program was carried out to see how teachers were able to implement this approach and how to increase students' reading literacy competence as well as teacher and student perceptions of this approach.

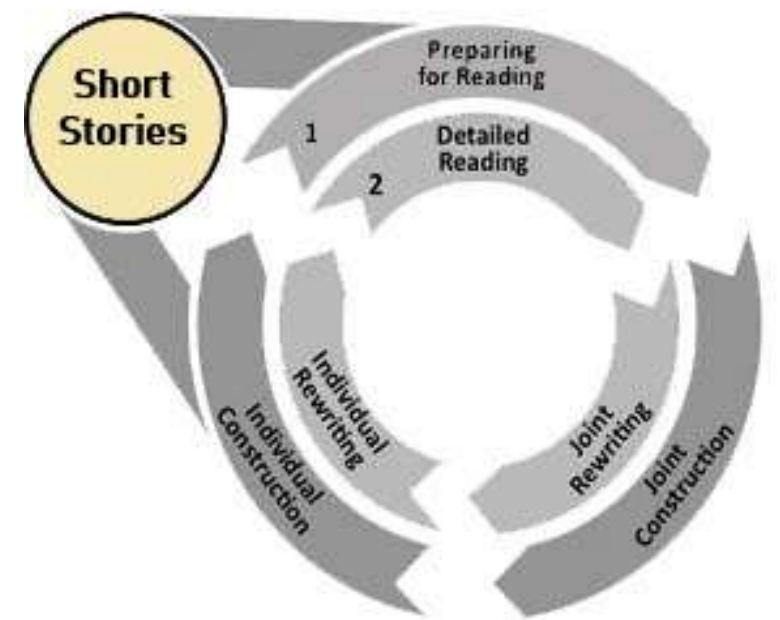

Figure 1. The R2L Stages by Martin and Rose (2012)

For this reason, with a collaborative research scheme, collaboration between universities, namely Medan State University and State Junior High School 3, this research is carried out which seeks to uncover various issues including the ability of teachers to plan, carry out learning, followed by discovering how teachers and students perceive this approach as well as problems. what arises in the implementation of the R2L Approach which is still newly introduced in Indonesia.

The implementation of the R2L Approach was carried out on learning competence reading short stories because reading short stories can be the basis for students' ability to read other stories. For example, reading novels, reading biographies, reading autobiographies, and so on. Another reason for choosing short stories is that so far students tend to be less interested in reading short stories. This can be seen during the teaching and learning process of literature. When students are given short story appreciation materials, it is very difficult for them to name the actors, setting, characters of the characters, and the theme of the story. Likewise, in learning literature, students are expected to be able to provide an explanation of the thoughts, ideas, imagination of the authors, so that students understand and understand the contents of short stories.

To achieve the expected curriculum goals in short story appreciation learning, teachers, especially teachers, are required to provide appropriate learning methods so that they can be used as minimal means to get maximum results. This is stated in (Sagala, 2004:63) that "As educators 
must understand various learning models that can stimulate students' ability to master the subject matter".

Thus, it is hoped that collaborative research between Medan State University Lecturers and Students with Teachers and Students of Medan State Junior High School 3 can give good results to describe the implementation of The R2L Approach in learning to read short stories.

\section{Research Methods}

The design of this research is descriptive qualitative. According to Denzin and Lincoln (2009) qualitative research is a field of inquiry in its own right. It mixs daisciplines, fields and subject matters'. Denzin and Lincoln further stated that Qualitative research is multi method focus in compromising an interpretive naturalistic qualification to each dicipline. This can be understood that qualitative investigator examine subject matter in their original contexts, demanding of understanding of, or making meaning objective in forms of the sense human being give to these things. Qualitative research covers the endeavour utilized and group of a number of scientific material-case research, private in-ward looking, ile account, discussion, monitoring, recorded, reciprocal and visible work that describes regular and difficult occurances and understanding person's live. Accordingly, expecting always to find a more qualified dose on the problem encounteredat (2009).

With the above statement Denzin and Lincoln argue that qualitative research is a variousmethod research that involves an interpretive naturalistic approach to the study material. By this qualitative endeavours investigate things in their natural contexts, trying to understand, or interpret phenomena in the context of the understanding within these subject matter. Qualitative research include the study of the utilization and collection of various empirical materials-case studies and visual texts in the form of personal introspection, stories, interviews, observations, history, interactions and those that describe routine and problematic moments and meanings in an personal's account. Therefore, it is hoped that there will always be better improvements in the phenomena studied (2009).

Bogdan and Biklen (2007) state 5 characteristics of qualitative research: (1) qualitative research has a original context as a straight spring of information and the analyst is the primary tools of research, (2) qualitative research is descriptive, (3) qualitative research prioritizes the process rather than just the outcome. and solutions, (4) in qualitative research the data are analyzed inductively (5) qualitative research with regard to meaning. Furthermore, Finch (1986) emphasizes the flexibility of qualitative research regarding the process and results in exploring meaning.

This research was conducted at SMPN 3 Medan in collaboration with Medan State University Lecturers. This study involved 2 lecturers at Medan State University, 2 Medan State University students, 2 language teachers at SMPN 3 Medan and 20 students and students in grade 8 at SMPN 3 Medan.

To obtain the data (qualitative and quantitative), several strategies were utilised (interview techniques, observation techniques, and survey strategies through written/online questionnaires and testament strategies) and typical of endeavour tools. Data gathering tools consist of (a) field notes (b) video (c) semi-structured interviews, questionnaires and document analysis. 
The examination technique utilized a qualitative descriptive investigation strategies following Huberman \& Miles which states that the data analysis includes three interrelated subprocesses, data reduction, namely data display, and judgement representation.

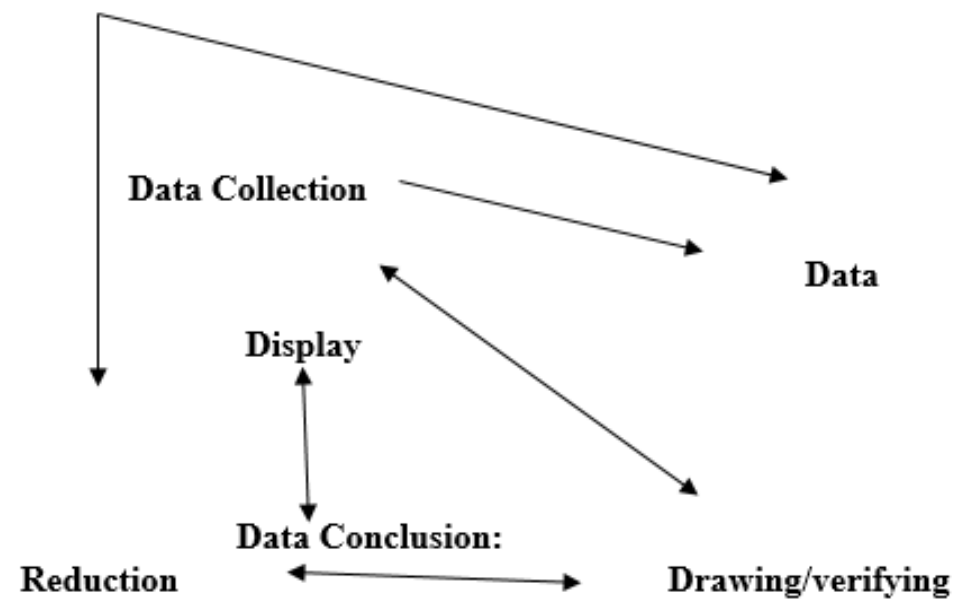

Figure 1. Component of Data Analysis: Interactive Model

\section{Results and Discussion}

The aim of this endeavour was to seek: (1) Planning for learning about short stories utilizing the Reading to Learn Approach); (2) Implementation of learning Short Stories using the Reading to Learn Approach;

For planning learning about short stories utilizing the Reading to Learn Approach, it was found that Teacher $\mathrm{N}$ and Teacher $\mathrm{E}$ both carried out fairly good preparations where they

a. Prepare learning tools such as RPP (Learning Implementation Plan), LKPD (Student Worksheet), teaching materials, assessments, learning media, tools (highlighter, origami, and Plano paper) as well as providing a tripod and cellphone to record the learning process

b. Prepare 5 or 6 texts according to students' needs and choices

c. Provide online learning directions through the WA (WhatsApp) group before entering class

Implementation of short story learning using the Reading to Learn Approach; in the implementation of learning it was found that the teacher followed the learning steps as stated by Rose and Martin (2012), namely

1. Preparation

2. Detailed Reading

3. Join Construction

4. Individual Construction

At the preparation stage, teacher $\mathrm{N}$ and teacher $\mathrm{E}$ both prepared the text that would be taught through the R2L approach. Furthermore, in preparing the text, the teacher tried to accommodate students' interests by providing a variety of texts so that students are motivated to read and follow the R2L learning steps. At the time of preparation the teacher also asked students to take turns reading the text to get the essence of the short story being studied.

Furthermore, at the Detailed Reading stage, the teacher asked previously one student to be assigned as a writer who was in charge of writing down keywords that were read by his classmates in the same class. At this stage, continuous teacher guidance was needed to find 
keywords correctly and precisely and to stabilize the color in the text given and the stages of the keywords chosen by students so that the selected keywords do not jump.

In the next step, namely Join Construction of Teacher $\mathrm{N}$ and teacher E. After all the keywords are written down, a classical join construction is carried out with the direction of the teacher in making sentences from the results of paraphrasing the keywords to completion through the participation of all students. In Teacher E's class, the Join Construction Group stage is carried out in 2 stages, namely Classical Construction and Group Construction.

In the Classical Construction stage, the teacher guided students to make sentences based on the key words that have been selected by the students. The teacher must ensure that the new sentence still retains the essence of the meaning of the sentence in the original text. This is done until all the key words have been developed into sentences.

Furthermore, Joint Construction activities were carried out at the Group level. Each group was asked to select the text they wanted from the existing text. The group then carried out the detailed reading stage again, reading the text and studying the key words and highlighting the color of the key words. One student in the group was assigned with writing down key words on flannel paper that has been prepared by the teacher, followed by doing joint construction at the group level and writing down the results on flannel paper. After finishing rewriting the key information into a new sentence, students presented the results of their group work through the attached Plano paper. After making the presentation, the other groups gave their responses.

In teacher class $\mathrm{E}$, one text was divided into several paragraphs which were selected for joint construction from classical to individual. With the text provided, students did a detailed reading. Then, students presented the results of their group work through the attached Plano paper. After making a presentation, the other groups gave their responses.

Likewise, in class, teacher $\mathrm{N}$ is in the process of joining classical construction until the group is provided with a different text. Each process the text given to each group is the same. The first day 1 short paragraph for the group. Second day of new slightly longer text. The third day was more mature. One group consists of 5 people. As a teacher, I buy tips for paragraphs to save time. Plano paper media adds to the creativity of students in presenting their work.

The last stage is individual constructionIn grades IX-K, individual join construction becomes homework because time is limited. To ensure that students can carry out individual construction, the teacher provides several examples of individual construction so that students can do it at home.

All steps taken were first to introduce students to the R2L model which was a new learning model for them. Furthermore, to ensure students can take advantage of this new approach, the teacher must carry out step by step thoroughly so that learners comprehend first the sense of the narration, again the reading process, paraphrasing, join construction, so that they can get to the creativity stage in creating texts but not eliminating the meaning. the original.

\section{Process of implementing R2L Activities}

\section{a. 1st Meeting}

At the first meeting, the students were presented with a short story text entitled 'Rahasia Ranti' by Fadillah TA for classical R2L, as many as 2 paragraphs. For group and individual R2L activities from the same text but with 2 paragraphs of different paragraphs. At the first meeting, 
the learning focused more on explaining the intrinsic elements of the short story, the R2L steps had not been carried out optimally, however, the teacher provided an understanding of the keywords. The students only completed steps R2L in 3 sentences. Students are still not able to determine the keywords of a sentence well.

\section{b. 2nd Meeting}

For the second meeting, using an ingenious piece of text from Pino's short story by Sarah Nafisah, 1 paragraph for classical R2L, 1 paragraph for group R2L and 1 paragraph for individual R2L. At the second meeting, the explanation of the intrinsic element was finished, and the implementation of R2L had gone better than the first meeting. However, it is still not optimal, students are still not familiar with the R2L steps. To advance to carry out R2L classical students must be appointed first. Students have begun to understand the concept of key words in note making, although they have not maximally determined keywords, students still think that all words in a sentence are important.

\section{c. 3rd Meeting}

For the third meeting, the classical R2L activity used pieces of short story text entitled "The journalist awaits the final trial" by Djoko Darmono's work, with 2 paragraphs, 2 paragraphs in group R2L and 2 individual R2L paragraphs. At the third meeting the students were already active. The steps of R2L were very unexpected, students already felt familiar with the steps of R2L that had worked optimally. In classical R2L, students have started to want to come forward voluntarily. Students already understand very well about note making and join construction. Students already understand about note making and can carry out note making well. The students were able to present the products of R2L in front of the class in groups. The students felt they were better than their classmates who did not participate in R2L activities.

\section{d. 4th Meeting}

In the fourth meeting, the R2L activity used a short story entitled 'Not Easy Again' by Sarah Nafisah, the classical R2L activity used 1 paragraph fragment, the group R2L 1 paragraph section, and 5 individual paragraph pieces. At the 4th meeting, the implementation of $\mathrm{r} 2 \mathrm{l}$ has exceeded expectations, the result of R2L created by sisea has reached 2-3 times the length of the original text. Students are very able to choose keywords and do note making maximally. Students compete to come to the front of the class to carry out classical R2L and R2L product presentations in groups and post them back to social media Instagram

From the explanation given, it can be said that at each stage of the meeting in learning, there is an increase in the expected achievements which are getting better day by day. It is clear that students enjoy the learning process with pleasure because they can explore the power of imagination with their own creativity through the R2L method, namely: keywords, paraphrase and joint construction and individual construction.

The findings of this study supported research result of Ika Lestari Damayanti (2016) From Storytelling to Story Writing: The Implementation of Reading to Learn (R2L) Pedagogy to Teach English as a Foreign Language in Indonesia. Study of Ika Damayanti research fund out that Reading to Learn supported students be more active for their own learning, the explicit teaching implemented by the teacher participants of this study assisted the students to develop control over their academic literacy. The introductory phase of the approach become crucial in driving students' attention into the text being learned. Shortly the recontextualization of R2L approach in this study drives learning experiences that bridge this teacher- fronted teaching to students' independent learning. The students' involvement in all the stages with more supports 
given by the teacher in the Detailed Reading stage, the students explored linguistic resources in the text learned.

In addition to the new horizon the teachers have on introduction to the use of The Reading to Learn Approach, there are also some challenges in the implementation. There are three main aspects faced by the teachers regarding justification and core understanding, time constrains for full impelentation of the R2L and students' different backround as their readiness to using this approach.

Regarding the challenges of using R2L, this study found that knowledge of R2L pedagogy, limited teaching time and different learning needs are three main issues faced by Chinese teachers. This also in line with the study of Xian Han Huay, Mark Shin Kee Shum and Chung Pui Tai Dan Shi mentioning the result of their research in which teachers also got problems in the implementation of the R2L namely in terms of teachers limited knowledge on the R2L, limitation in terms of time and students readeiness in using this $\mathrm{R} 2 \mathrm{~L}$ in terms of active participation for some students.

\section{Conclusion}

The purpose of this study was to determine: (1) Planning for learning about short stories using the Reading to Learn Approach); (2) Implementation of learning Short Stories using the Reading to Learn Approach. Based on the results of the study, it was concluded that the teacher had carried out good preparation in planning R2L-based learning, namely by preparing learning tools in the form of lesson plans, teaching materials, worksheet, assessment and learning media, the teacher also informed students beforehand that the teacher would apply a new learning model which was expected All students participate fully in the class later. At the implementation stage of learning the teacher has followed the R2L learning steps by Rose and Martin (2012), namely Preparation, Detailed Reading, Joins Construction and Individual Construction.

Based on the results of the study, it is suggested to teachers to be able to learn and apply the R2L Approach in teaching short story texts. Likewise, school principals are expected to strengthen and facilitate teachers to understand and then apply the R2L Approach to reading literacy learning in schools.

\section{References}

Acevedo, C. (2010). Will the implementation of Reading to Learn in Stockholm schools accelerate literacy learning for disadvantaged students and close the achievement gaps?Stockholm: Multilingual Research Institute.

Astuti, R.W., Waluyo, H.J., and Rohmadi, M. (2019). Character Education Values in Animation Movie of Nussa and Rarra. Budapest International Research and Critics Institute-Journal (BIRCI-Journal). P. 215-219.

Azhar, A. (2018). Students' Trends in Islamic Communication Postgraduate in2010-2016 State Islamic University of North Sumatera (UINSU). Budapest International Research and Critics Institute (BIRCI-Journal), P.206-214.

Bogdan, RC, \& Biklen, SK (2007) Qualitative Research for Education: An Introduction to Theory and Methods. Allyn and Bacon, Inc.

Damayanti, Ika Lestari 2017From Storytelling to Story Writing: The Implementation of

Denzin, Norman. K., \& Lincoln, Yvonna S (Eds) (2009). Handbook of Qualitative Research. California: Sage Publications, Inc. 
Huberman, M., A., \& Miles, M B. (1994) Data Management and Analysis Method. In Denzin NK, \& Lincoln, YS (Eds), Handbook of Qualitative Research: California Sage Publications, Inc

Martin, J. (2009). Genre and language learning: A social semiotic perspective. Linguistics and Education, 20, 10-21.

Martin, J., \& Plum, G. (1997). Constructing experience: some story genres. (M. Bamberg, Ed.) Journal of Narrative and Life History, 7((1-4)), 299-308.

Martin, J., \& Rose, D. (2008). Genre Relations: Mapping Culture. London: Equinox Publishing Ltd.

Martin, J., Matthiessen, CM, \& Painter, C. (1997). Working with functional grammar. London: Arnold.

Nurgiyantoro, Burhan. 2005. Theory of Fiction Studies. Yogyakarta: Gajah MadaUniversity Press.

Reading to learn (R2L) Pedagogy to Teach English as a Foreign Language in Indonesia. Indonesian Journal of Applied Linguistics. Vol 6. No 2 January pp 229-242

Rose, D. (2018). Languages of Schooling: Embedding literacy learning with genre-based pedagogy. European Journal of Applied Linguistics, 6(1), 31-57. doi: 10.1515/eujal-20170008.

Rose, D., \& Martin, J. (2012). Learning to Write, Reading to Learn. Genre, Knowledge andPedagogy in the Sydney School.Sheffield/Bristol: Equinox.

Sahiruddin. (2013). The Implementation of the 2013 Curriculum and the Issues of English Language Teaching and Learning in Indonesia. The Asian Conference on Language Learning 2013 (pp. 567-574). Osaka: IAFOR.

Saleh, A., Mujahiddin. (2020). Challenges and Opportunities for Community Empowerment Practices in Indonesia during the Covid-19 Pandemic through Strengthening the Role of Higher Education. Budapest International Research and Critics Institute-Journal (BIRCIJournal). Volume 3, No 2, Page: 1105-1113

Shum, MSK, Shi, D., \& Tai, CP (2019). The effectiveness of using 'reading to learn, learning to write' pedagogy in teaching Chinese to non-Chinese speaking students in Hong Kong. International Journal of Language and Lingusitics. August

Shum, MSK, Tai, CP, \& Shi, D. (2018). Using 'Reading to Learn' (R2L) pedagogy to teach discussion genre to non-Chinese-speaking students in Hong Kong. International Journal of Bilingual Education and Bilingualism, 21(2), 237-247. doi:10.1080/13670050.2016.1159653.

Tarigan, HG (1979). Reading as a Language Skill. Bandung: Space.

Widodo, HP (2015). Engaging Students in Literature Circles: Vocational English Reading Programs. Asia-Pacific Education Researcher (Preprints), 1-13.

Xian Han Huang, Mark Shiu Kee Shum, Chung Pui Tai, Dan Shi, Using Reading to Learn Pedagogy to Improve Chinese Writing among Ethnic Minority Students in Hong Kong: A Quasi-experimental Study, International Journal of Language and Linguistics. Vol. 7, No. 5, 2019, pp. 202-212. doi: 10.11648/j.ijll.20190705.14

Yang, C. (2009). A case study of the use of short stories in a junior secondary ESL classroom in Hong Kong. The International Journal of Learning, 16(1), 35-50. 